\title{
Fecal MicroRNAs as Potential Biomarkers for Screening and Diagnosis of Intestinal Diseases
}

\author{
Humaira Rashid ${ }^{*}$, Biplob Hossain', Towfida Siddiqua ${ }^{2}$, Mamun Kabir', Zannatun Noor' \\ Mamun Ahmed ${ }^{3}$ and Rashidul Haque ${ }^{1}$
}

${ }^{1}$ Emerging Infections and Parasitology Laboratory, International Centre for Diarrhoeal Disease Research, Dhaka, Bangladesh, ${ }^{2}$ Nutrition and Clinical Services Division (NCSD), International Centre for Diarrhoeal Disease Research, Dhaka, Bangladesh, ${ }^{3}$ Department of Biochemistry and Molecular Biology, University of Dhaka, Dhaka, Bangladesh

\section{OPEN ACCESS}

Edited by:

Mario Hiroyuki Hirata,

University of São Paulo, Brazil

Reviewed by:

Juntaro Matsuzaki,

University of California,

San Francisco, United States

Giuseppe Losurdo,

University of Bari Aldo Moro Medical

School, Italy

Michele Barone,

University of Bari Aldo Moro, Italy

${ }^{*}$ Correspondence:

Humaira Rashid

humairarashid777@gmail.com;

humaira.rashid@icddrb.org

Specialty section:

This article was submitted to

Molecular Diagnostics

and Therapeutics,

a section of the journal

Frontiers in Molecular Biosciences

Received: 27 February 2020

Accepted: 10 July 2020

Published: 07 August 2020

Citation:

Rashid H, Hossain B, Siddiqua T,

Kabir $M$, Noor Z, Ahmed $M$ and Haque $R$ (2020) Fecal MicroRNAs as

Potential Biomarkers for Screening

and Diagnosis of Intestinal Diseases.

Front. Mol. Biosci. 7:181.

doi: 10.3389/fmolb.2020.00181
MicroRNAs (miRNAs) are a class of conserved endogenous, small non-coding RNA molecules with a length of 18-25 nucleotides that regulate gene expression by RNA interference processes, including mRNA chopping, mRNA deadenylation, and translation inhibition. miRNAs maintain the physiological functions of the intestine and are instrumental in gut pathogenesis. miRNAs play an important role in intercellular communication and are present in all body fluids, including stools with different composition and concentrations. However, under diseased conditions, miRNAs are aberrantly expressed and act as negative regulators of gene expression. The stable and differentially expressed miRNAs in stool enables miRNAs to be used as potential biomarkers for screening of various intestinal diseases. In this review, we summarize the expressed miRNA profile in stool and highlight miRNAs as biomarkers with potential clinical and diagnostic applications, and we aim to address the prospects for recent advanced techniques for screening miRNA in diagnosis and prognosis of intestinal disorders.

Keywords: fecal miRNA, intestinal barrier dysfunction, inflammatory bowel disease, colorectal cancer, qPCR, microarray, dPCR

\section{INTRODUCTION}

MicroRNAs (miRNAs) are small non-coding RNAs in the range 18-25 nucleotides in length that act as regulators for post-transcriptional gene expression. The biogenesis of miRNAs is a complex multi-step process that begins in the nucleus (Figure 1). To form mature miRNAs, RNA polymerase II transcribes miRNA genes, to generate a primary miRNA (primiRNA), which is subsequently cleaved by Drosha (RNase III endonuclease), resulting in a precursor miRNA (pre-miRNA) (Wan et al., 2016). The pre-miRNA is cleaved by the cytoplasmic endonuclease Dicer and forms a mature miRNA duplex (O'Brien et al., 2018). One strand of the mature miRNA is loaded onto an Argonaute (Ago) protein forming a RNA-induced silencing complex (RISC) (Hammond et al., 2000; Wu et al., 2006). The mature miRNA functions by guiding the Ago protein and associated factors to target sites in the $3^{\prime}$ untranslated region (UTR) of mRNA. Typically, miRNA base-pairs with target mRNA, and the degree of complementarity between miRNA and target mRNA determines the repression of translation or reduction of target mRNA stability. A complete base pairing between the seed region of active miRNA and $3^{\prime}$ UTR of target mRNA promotes the degradation of mRNA, 


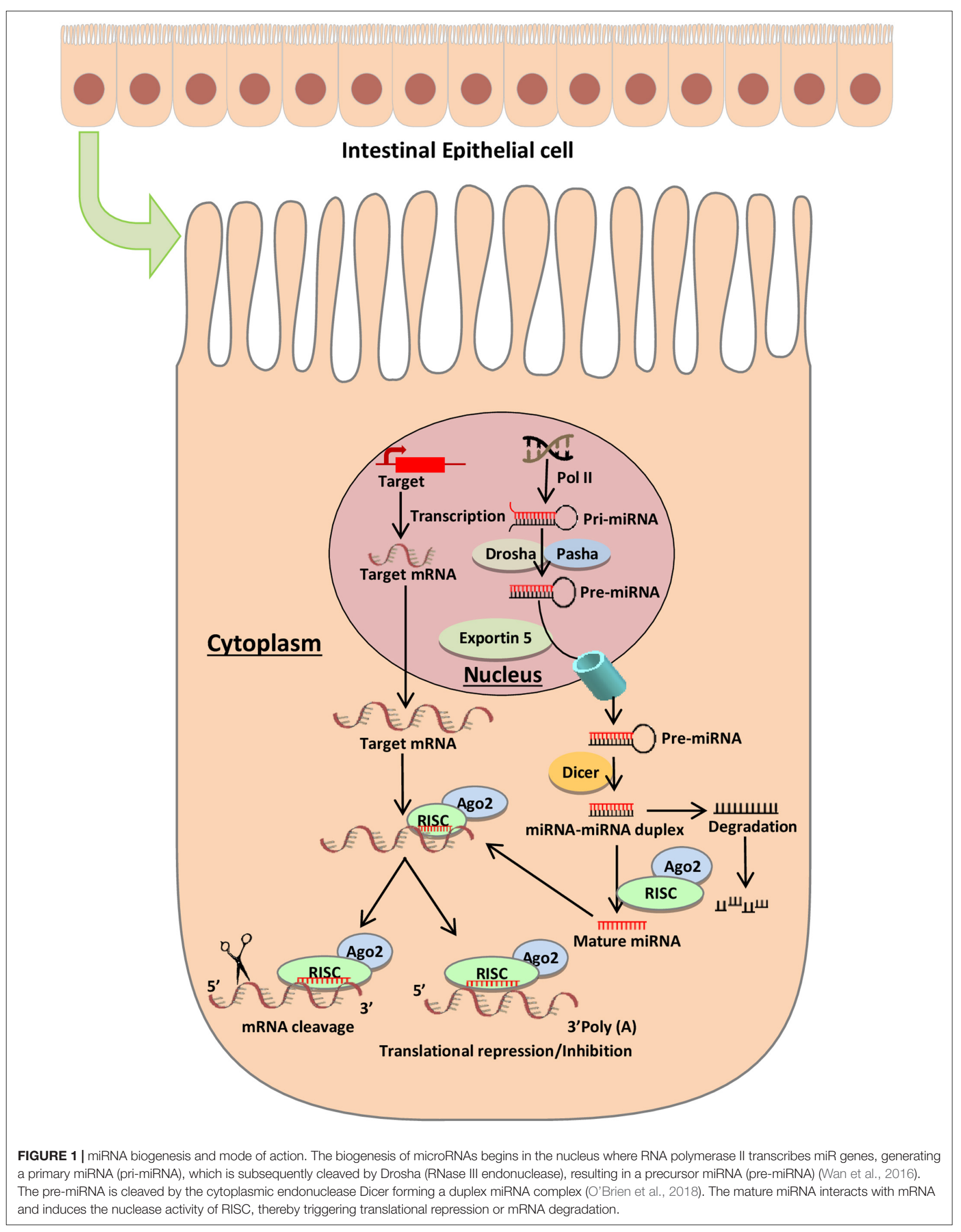


while the incomplete base pairing represses the translation initiation or elongation processes and promotes deadenylation followed by degradation of target mRNA in processing bodies (Valencia-Sanchez et al., 2006; Wu et al., 2006). miRNAs regulate the expression levels of thousands of target genes involved in different pathways and plays an important role in a variety of cellular and developmental processes (Ivey and Srivastava, 2015). miRNAs participate in intercellular communication and are isolated from body fluids, including stools (Moloney et al., 2018).

Although the function of extracellular miRNA in body fluids is not well characterized, the differentially expressed stable miRNAs in stool under diseased condition could be used as a potential biomarker for screening of intestinal diseases. In this review, we discuss the potential use of fecal miRNAs as molecular markers for screening and diagnosis of intestinal pathologies. Furthermore, we aim to address the prospects for recent advanced techniques for screening miRNA for specific disease in diagnosis and prognosis.

\section{FECAL miRNAs AS POTENTIAL BIOMARKERS FOR INTESTINAL BARRIER DYSFUNCTION}

Intestinal epithelial barrier is a complex anatomical and functional structure of gut lumen that allows the selective absorption of essential nutrients and fluids and acts as a barrier against toxins and microorganism invasions (Groschwitz and Hogan, 2009). Disruption of this barrier can trigger various intestinal diseases, characterized by increase in intestinal permeability (Fukui, 2016). It has been found that intestinal epithelial barrier dysfunction is more prevalent among the residents of low- and middle-income countries (LMICs) where the sanitation is often poor and hygiene practice is suboptimal (Mondal et al., 2012; Petri et al., 2014). Studies have revealed that children with enteric dysfunction have an impaired intestinal permeability that can lead to inflammatory bowel syndrome (IBS) and other inflammatory-related gut pathologies (Shulman et al., 2008). It is critically important to prevent the invasion of pathogenic microorganisms in order to maintain the integrity of gut epithelia. Repeated exposure to fecal pathogens, toxins, irritants, and pro-inflammatory cytokines can disrupt the tight junction's barrier function, causing inflammation and facilitating the permeation of pro-inflammatory molecules such as unwanted colonial bacteria, bacterial antigens, and toxins to cross through and exacerbate the immune response (Fukui, 2016; Hossain et al., 2016). In different studies, it has been shown that infections caused by enteric protozoa, rotavirus, astrovirus, enterovirus, adenovirus, and enterotoxigenic Escherichia coli have an association with the aberrant expression of host cellular miRNAs that has a profound impact on child growth and development (Buret et al., 2002; Skalsky and Cullen, 2010; Zheng et al., 2013; Maudet et al., 2014; Ho et al., 2016; Zhou et al., 2016). miRNAs are highly relevant for infection-induced intestinal disorders as recent research has revealed their role in regulating the inflammatory responses and subsequently gastrointestinal diseases (Sheedy and O'neill, 2008; Bi et al., 2009).
Current evidence suggests that fecal miRNA could mediate dysbiosis-related inflammation of the host (Viennois et al., 2019). A previous study showed the perfect balance between microbiota composition and host metabolism and immunity (Liu et al., 2016). Alteration of gut microbiota composition is associated with intestinal barrier dysfunction that can cause inflammatory bowel disease (IBD) and colorectal cancer (CRC) (Belkaid and Naik, 2013; An et al., 2014; Yu, 2018). In addition, miRNAs have been shown to play a critical role in modulating viral infections such as rotavirus, enterovirus, which is largely responsible for gastroenteritis and alterations in enterocytes and bacterial microflora (Buret et al., 2002; De Magistris et al., 2003; Mondal et al., 2012; Maudet et al., 2014; Zhou et al., 2016).

More recently, miRNAs have attracted a great deal of attention due to their role as key regulators of inflammation. Aberrant expression of miRNAs can play a pathogenic role in diseases, including those primarily affecting the gut (Figure 2). Cichon et al. (2014) reported that the intestinal barrier function is impaired in a typical Dicer1-deficient mouse model (i.e., absence of mmu-miR-192), resulting in spontaneous intestinal inflammation. Of note, miRNAs, such as miR-122a and miR21 , target negative regulators of immune response to promote inflammation (Ye et al., 2011; Zhang et al., 2015, 2017). Several investigations reveal that inflammatory cytokines such as tumor necrosis factor (TNF)- $\alpha$ and interferon gamma $(\mathrm{IFN} \gamma)$ may increase greatly the expression of miRNAs in enterocytes, cultured cells, and intestinal tissues (Ye et al., 2011; Haines et al., 2016). Lin et al. reported that TNF- $\alpha$ increased the expression of miR-21, which significantly increased barrier permeability (Zhang et al., 2015). Activation of these proinflammatory cytokines may induce barrier disruption and increased intestinal permeability.

The pathophysiological mechanisms of intestinal barrier dysfunction are multifaceted and not fully understood. Although miRNA has been mostly studied in vitro using cell lines, over the past few years, there is a growing interest in how miRNAs may act as a molecular marker to detect intestinal barrier dysfunction. Importantly, stool miRNA due to its stability, preservation, and high abundance may serve as potential biomarkers for screening and diagnosis of various intestinal disorders in patients in developing countries.

\section{FECAL miRNAs AS POTENTIAL BIOMARKERS FOR VARIOUS INTESTINAL DISEASES}

Deregulation of miRNAs is linked with numerous diseases such as cancer (Lin and Gregory, 2015), hepatitis, cardiovascular (McManus and Ambros, 2011), neurodegenerative, and gastrointestinal diseases (Absalon et al., 2013). Studies have revealed that miRNAs can be secreted in body fluids including serum, urine, breast milk, and saliva, and in stool in encapsulated form within exosome (Turchinovich and Cho, 2014). Exosomes incorporating miRNA act as signaling molecules for mediating cell-to-cell communication and protects the miRNAs from degradation (Montecalvo et al., 2012; Wahlgren et al., 2012). 


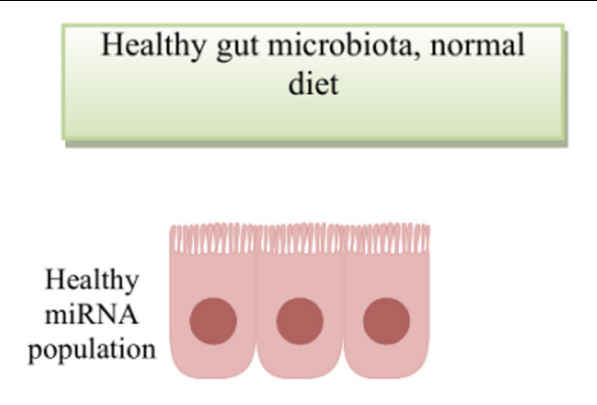

Fecal pathogens, toxins, irritants
and pro-inflammatory cytokines
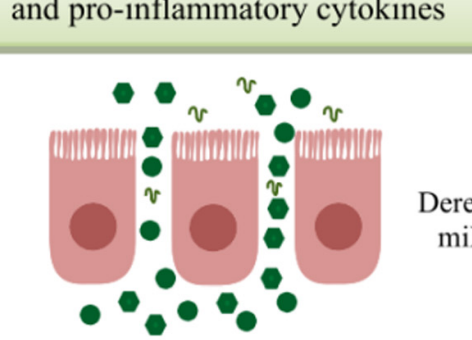

Deregulated miRNAs

Increase intestinal permeability, intestinal barrier dysfunction

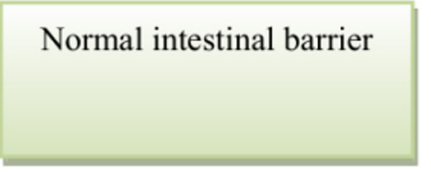

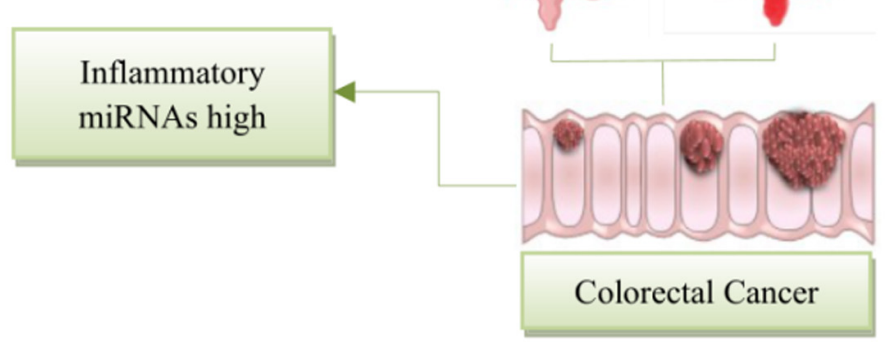

FIGURE 2 | Schematic diagram represents the potential role of miRNA expression in intestinal diseases. The miRNA network plays a critical role in regulating gene expression in health and disease. miRNAs are essential regulators of inflammation. Post intestinal barrier damage, persistent inflammatory conditions can change the expression of microRNA, initiating or developing IBD. When IBD persists for a long period of time, the chronic dysregulation of miRNAs targets transcripts that encode intestinal barrier components and tumor-suppressor miRNAs, and this can lead in the disease development from IBD to CRC.

miRNAs embedded in exosomes provide stability to miRNAs in feces and other fluids and protects from RNase degradation (Koga et al., 2011). The sensitive and specific detection of miRNAs in the extracellular environment has contributed to screening and diagnosis of therapeutic and prognostic biomarkers for multiple diseases. Numerous studies have revealed the association between dysregulation of miRNA and disease progression and validated miRNAs as potential biomarkers of neoplastic and non-neoplastic diseases.

Biomarkers are important for early detection of the disease and early detection could prevent malignancies and improve prognosis. Therefore, it is necessary and important to develop a method that would be affordable and safe with relatively high sensitivity and specificity. Approaches for the screening of IBD and CRC have been performed on feces like colonoscopies, flexible sigmoidoscopy, fecal occult blood test (FOBT), and the fecal immunochemical test (FIT). While colonoscopies and sigmoidoscopy are highly reliable screening tools for detecting IBD and CRC (Kato et al., 2016; Spiceland and Lodhia, 2018), they are invasive and costly, and thus impeding screening compliance. FOBT, which commonly detects blood in stool, is non-invasive and a better approach to screen IBD and CRC (Simadibrata, 2010); however, FIT, which measures the concentration of hemoglobin in feces by using an antibody that targets human hemoglobin, is recommended over FOBT as a non-invasive approach. These methods either have a significant sensitivity or specificity but not both (Link et al., 2010; Iannone et al., 2016).

MicroRNAs, which are remarkably stable and reproducibly detected even after a long-term storage of fecal samples for a number of years (Wohnhaas et al., 2020), are disease specific. Aberrant expression of fecal miRNAs in IBD and CRC explores miRNAs as potential non-invasive clinical biomarkers. Previous studies have isolated RNA from human stool and identified 
miRNAs as potential biomarkers for colon and pancreatic malignancies (Ahmed et al., 2009; Link et al., 2012). In another study, the total RNA isolation from stool and miRNA expression analysis has revealed that miR-21 and miR-106a are highly expressed in patients with CRC, indicating the feasibility of potential biomarkers for the development of non-invasive screening test of colorectal neoplasia (Link et al., 2010). In addition to diagnosis of cancer including distinguishing tissue origin or site, cancer subtypes, and detecting cancer at early stage, miRNA signatures can also facilitate to predict cancer prognosis, which has recently been suggested by a growing body of research (Li et al., 2010; Zhang et al., 2013). For example, the expression of fecal MiR-21 may be a potential and minimally invasive prognostic biomarker of CRC (Hibner et al., 2018), which need to be evaluated and validated in well-defined large cohorts of carefully selected cases.

Dysregulation of miRNA expression in intestine is related to different disease and provides the information to define new miRNA biomarkers; for example, the altered expression profile of fecal miRNA composition in active IBD patients versus control has been identified and fecal miR-223 and miR-1246 are found upregulated in the stool of active IBD patients (Verdier et al., 2019). Another study identified the highest expression of miR-21, miR-155, and miR-223 in feces of IBD patients and overexpression of miR-21 has been shown to cause intestinal epithelial barrier impairment. ROC curve analysis using miR223 in feces showed that the diagnostic accuracy for active UC was (AUC: 0.93 ) with a specificity and sensitivity of 86.7 and 90\%, respectively (Yang et al., 2013; Schönauen et al., 2018). Bastaminejad et al. (2017) showed that miRNA-21 expression in stool could be a promising biomarker for the diagnosis of CRC with a sensitivity and a specificity of 86.05 and $81.08 \%$ (AUC: $0.829)$, respectively.

Ahmed et al. (2009) initially detected the miRNA expression in the stool of CRC patients and identified the increased expression of seven miRNAs including miR-21, miR-106a, miR-96, miR-203, miR-20a, miR-326, and miR-92 and decrease in the expression of seven other miRNAs, miR-320, miR-126, miR-484-5p, miR143, miR145, miR-16, and miR-125b, in the stool of CRC patients (Table 1). Ahmad et al. also selected a panel of fecal miRNAs where 12 miRNAs (miR-7, miR-17, miR-20a, miR-21, miR-92a, miR-96, miR-106a, miR-134, miR-183, miR-196a, miR-199a-3p, and miR214) were upregulated in the feces of CRC patients and 8 miRNAs (miR-9, miR-29b, miR-127-5p, miR-138, miR143, miR-146a, miR-222, and miR-938) were downregulated in the feces of CRC patients. These miRNAs could differentiate CRC incidences from healthy controls and also different TNM stages with a high sensitivity and specificity (Ahmed et al., 2013). A comparative study of fecal miRNA expression profile by microRNA microarray demonstrated that the two miRNAs (miR-221 and miR-18a) that are highly expressed in stool of CRC patients with a sensitivity and specificity of 66 and 75\%, respectively (AUC: 0.75) have a potential to be used as a noninvasive biomarker for screening of CRC (Yau et al., 2014). In addition, the significant decrease in the expression levels of miRNA-29, miRNA-223, and miRNA-224 have been detected in CRC patients, while in rectum cancer patients, the miRNA-29 is overexpressed (Zhu et al., 2016). The ROC curve analysis found that the AUC values were 0.777 for miR-29a with a sensitivity of $85 \%$ and a specificity of $61 \%, 0.649$ for miR-223 with a sensitivity of $60 \%$ and a specificity of $71 \%$, and 0.744 for miR-224 with a sensitivity and specificity of 75 and $63 \%$, respectively.

In particular, miRNAs, being a robust biomarker for CRC and IBDs, provide an opportunity to be used as a non-invasive biomarker to detect various intestinal diseases with a high sensitivity and specificity.

\section{EXPERIMENTAL APPROACHES FOR ISOLATION, DETECTION AND QUANTIFICATION OF FECAL MIRNA}

MicroRNAs have been detected in almost all body fluids including stool (Weber et al., 2010; Moloney et al., 2018), in a remarkably stable form. The stability of miRNAs plays an important role in shaping miRNA expression profile and makes it feasible for accurate measurement and detection. Several techniques have been developed to analyze the altered miRNA expression profile and the identification of targets in different intestinal diseases. The specific and sensitive methods for extraction and detection reveal the potential of miRNAs in diagnostics, prognosis, and therapy.

\section{miRNA Isolation From Fecal Samples}

There are several methods used in different studies for miRNA extraction from biofluids including stool samples (Iborra et al., 2013; Wu et al., 2014; Ren et al., 2015). To provide highquality miRNA, a number of studies have focused on the technical optimization of miRNA extraction. Guanidiniumphenol-based solutions, such as TRIzol/TRI reagent, are a convenient and effective method for miRNA extraction from stool samples. The TRIzol method is cost-effective, which yields good-quality miRNA, removes the inhibitors, and does not rely on specialized equipment (Paula et al., 2003). The application of the TRIzol/TRI-Reagent after bead beating followed by alcohol precipitation is the most widespread method for the isolation of total RNAs including miRNAs. However, miRNA extractions using the TRIzol method have the risks of cross-contamination of phenol, DNA, lipid or proteins. Combination of TRIzolbased lysis and spin column-based extraction has been found to yield high, ultra-pure miRNA for sensitive downstream processes (Yau et al., 2014). miRNeasy extraction kit in combination with phenol/guanidine-based lysis has strong efficiency in removing inhibitors, exogenous and intrinsic, and the purification of RNA greater than 18 nucleotides for downstream applications. Other commercially available kits - Norgen's Stool Total RNA Purification Kit, Macherey-Nagel's NucleoSpin RNAs stool kit, E.Z.N.A ${ }^{\mathrm{TM}}$ stool RNA Kit (OMEGA, GA, United States), etc. have been used in different studies for the extraction of ultrapure high-quality miRNAs (Ren et al., 2015). For exosomal RNA extraction, the immunomagnetic beads conjugated with target antibody are used for exosome isolation. The exosomes isolated are homogenized and miRNAs are extracted using the RNA extraction kits for downstream applications (Koga et al., 2011). 
TABLE 1 | Key findings of studies involving fecal miRNA expression in patients with intestinal diseases.

\begin{tabular}{|c|c|c|c|c|}
\hline Study type & Study participants & Age & Key findings & References \\
\hline $\begin{array}{l}\text { Proof-of-principle study using } 2 \\
\text { independent patient cohorts }\end{array}$ & $\begin{array}{l}\text { Patients: } \\
\text { (i) CD: } n=39 \\
\text { (ii) UC: } n=18 \\
\text { (iii) Control: } n=15\end{array}$ & $\begin{array}{l}\text { Patients: } 12-50 \text { years } \\
\text { (i) CD: } 36.6 \pm 12.3 \text { years } \\
\text { (ii) UC: } 44.9 \pm 15.8 \text { years } \\
\text { Control: } 53.5 \pm 16.8 \text { years }\end{array}$ & $\begin{array}{l}\text { Higher expression in IBD stool } \\
\text { samples was shown in miR-223, } \\
\text { miR-155, miR-16, and miR-21. }\end{array}$ & $\begin{array}{l}\text { Schönauen } \\
\text { et al., } 2018\end{array}$ \\
\hline Case-control study & $\begin{array}{l}\text { Patients: } \\
\text { (i) IBD: } n=10 \\
\text { (ii) Cancer: } n=15 \\
\text { (iii) Normal: } n=5\end{array}$ & Adults & $\begin{array}{l}\text { miR-21, miR-106a, miR-96, } \\
\text { miR-203, miR-20a, miR-326, } \\
\text { and miR-92 showed increased } \\
\text { expression in stool of CRC } \\
\text { patients and miR-320, miR-126, } \\
\text { miR-484-5p, miR-143, miR-145, } \\
\text { miR-16, and miR-125b showed } \\
\text { decreased expression in stool } \\
\text { (and also in tissue) of CRC } \\
\text { patients. } \\
\text { miRNAs from stool of UC } \\
\text { patients was upregulated for four } \\
\text { miRNAs (miR-21, miR-203, } \\
\text { miR-126, and miR16), and } \\
\text { downregulated for two miRNAs } \\
\text { (miR-320 and miR-192). }\end{array}$ & $\begin{array}{l}\text { Ahmed et al., } \\
2009\end{array}$ \\
\hline Case-control study & $\begin{array}{l}\text { Patients: } \\
\text { (i) CD:(active: } n=22 \text {; inactive: } \\
n=22 \text { ) } \\
\text { (ii) UC:(inactive: } n=11 \text {; active: } \\
n=24 \text { ) } \\
\text { (iii) Control: } n=23\end{array}$ & $\begin{array}{l}\text { Patients: } 27-69 \text { years } \\
\text { Control: } 25-73 \text { years }\end{array}$ & $\begin{array}{l}\text { miR-223 and miR-1246 are } \\
\text { present at high levels in stool } \\
\text { and are increased in active IBD } \\
\text { patients. }\end{array}$ & $\begin{array}{l}\text { Verdier et al., } \\
2019\end{array}$ \\
\hline Case-control study & $\begin{array}{l}\text { Patients: } n=17 \\
\text { Healthy subjects: } n=28\end{array}$ & $\begin{array}{l}\text { Patients: } 46-80 \text { years } \\
\text { Healthy participants:36- } 79 \text { years }\end{array}$ & $\begin{array}{l}\text { Fecal miR-135b, miR-223 and } \\
\text { miR- } 451 \text { was significantly } \\
\text { upregulated in CRC patients. }\end{array}$ & $\begin{array}{l}\text { Phua et al., } \\
2014\end{array}$ \\
\hline Case-control study & $\begin{array}{l}\text { Patients: } \\
\text { Adenoma: } n=151 \text {, Advanced } \\
\text { Adenoma: } n=48, \\
\text { CRC: } n=198, \\
\text { Healthy subjects: } \\
n=198\end{array}$ & $\begin{array}{l}\text { Patients: } \\
\text { Adenoma: } 60.39 \pm 5.65 \text { years } \\
\text { Advanced Adenoma: } \\
58.73 \pm 6.78 \text { years, } \\
\text { CRC: } 66.53 \pm 11.05 \text { years } \\
\text { Healthy participants: } \\
58.65 \pm 6.87 \text { years }\end{array}$ & $\begin{array}{l}\text { Stool miR-221 and miR-18a } \\
\text { were significantly upregulated in } \\
\text { CRC stages I + II. There was no } \\
\text { significant upregulation in } \\
\text { adenoma or advanced adenoma } \\
\text { for both miR-221 and miR-18a. }\end{array}$ & Yau et al., 2014 \\
\hline $\begin{array}{l}\text { Retrospective case-control } \\
\text { study }\end{array}$ & $\begin{array}{l}\text { Patients: } n=80 \\
\text { Healthy subjects: } n=51\end{array}$ & $\begin{array}{l}\text { Patients: } 60.7 \pm 11.8 \text { years } \\
\text { Healthy participants: } \\
49.3 \pm 12.7 \text { years }\end{array}$ & $\begin{array}{l}\text { Fecal miRNA-29a, miR-223, and } \\
\text { miR-224 was significantly down } \\
\text { regulated in the stools of the } \\
\text { CRC patients. }\end{array}$ & Zhu et al., 2016 \\
\hline Case-control study & $\begin{array}{l}\text { Patients: } \\
\text { (i) Adenoma: } n=110 \\
\text { (ii) Advanced adenoma: } n=59 \\
\text { (iii) CRC: } n=104 \\
\text { (iv) IBD: } n=42 \\
\text { (v) Healthy participants: } n=109\end{array}$ & $\begin{array}{l}\text { Patients: } \\
\text { (i) Adenoma:58.9 } \pm 6.9 \text { years } \\
\text { (ii) Advanced adenoma: } \\
62.1 \pm 9.5 \text { years } \\
\text { (iii) CRC: } 66.8 \pm 11.9 \text { years } \\
\text { (iv) IBD: } 48.2 \pm 11.6 \text { years } \\
\text { (v) Healthy participants: } \\
60.4 \pm 7.0 \text { years }\end{array}$ & $\begin{array}{l}\text { Significantly higher level of } \\
\text { miR-135b, but not miR-31, was } \\
\text { detected in the stool samples of } \\
\text { CRC }(P<0.0001) \text { and } \\
\text { advanced adenoma. Relatively } \\
\text { low level of miR-135b detected } \\
\text { in stool of patients with IBD. }\end{array}$ & Wu et al., 2014 \\
\hline
\end{tabular}

Additional optimization and validation of extraction procedures is encouraged for high extraction efficiency and purity of miRNAs (Tarallo et al., 2014). miRNA extracted from the patient stool can then be used for quantification and miRNA profile analysis.

\section{Detection and Quantification of Fecal miRNAs Quantitative Real-Time PCR (qPCR)}

The screening and diagnosis of certain diseases rely heavily on invasive endoscopic techniques, which have several practical limitations such as bowel preparation and sedation. Therefore, an optimal screening procedure, preferably non-invasive diagnostic technologies, has a tremendous potential to increase survivorship. Many studies have reported and investigated the potential of miRNAs as diagnostic biomarkers where an efficient, robust, and standardized method for miRNA detection has been successfully produced to profile miRNAs.

Quantitative real-time polymerase chain reaction ( $q P C R)$ is a commonly used method for quantifying miRNA expression. Due to the small size, the traditional qPCR cannot be applied for quantification of mature miRNAs. Therefore, it is important 
to extend the length of mature miRNA before performing the qPCR for amplification and quantification. The stem-loop reverse transcription PCR is the most common method used for quantification of miRNA. This method uses stem-loop primer specific for the synthesis of first-strand cDNA of mature miRNA. The cDNA synthesized can be amplified using miRNA-specific forward primer and stem-loop reverse primer. The sensitive, specific miRNA hydrolysis TaqMan probe is used for fluorescence and quantification of mature miRNA expression (Chen et al., 2005). In another method, poly(A) polymerase is used to polyadenylate the $3^{\prime}$ end of all mature miRNAs, and the oligodT primer that has an adapter sequence at the $5^{\prime}$ end is employed to generate a cDNA (Shi and Chiang, 2005). A forward primer specific to miRNA and a universal reverse primer complimentary to adapter sequence is used for PCR amplification and SYBR Green-based real-time PCR for quantification (Ro et al., 2006). However, the traditional mature miRNA-qPCR has problematic issues when trying to discriminate closely related miRNAs that differ only in a few of the bases or when the RNA yield is very low. The Locked Nucleic Acid (LNA) primers have been developed that are remarkably specific to targets compared to DNA and RNA probes and can discriminate single-nucleotide mismatch (Owczarzy et al., 2011). A unique combination of two microRNAspecific LNA primers further increases specificity toward the detection of diagnostic biomarkers in challenging samples like stool. SYBR Green- and TaqMan qPCR-based expression analyses of stool miRNA were able to monitor changes at various stages of CRC, IBDs, and other intestinal diseases, allowing for reliable diagnostic screening of diseases (Ahmed et al., 2009, 2018b; Wu et al., 2012; Schönauen et al., 2018). The miRNA qPCR is a reliable screening method for biosignatures in clinical specimens with a high sensitivity for detection.

\section{Microarray Profiling}

Microarray-based expression analysis is a well-established, powerful, high-throughput, cost-effective technique capable of identifying a large number of candidate miRNA expression levels in one assay within a large number of samples processed in parallel in a single experiment (Thomson et al., 2007). Microarray has been extensively used to measure the expression profile of miRNA in stool (Link et al., 2012; Phua et al., 2014). For routine expression profiling, microarray is one of the most recent wellestablished hybridization techniques that utilize DNA probes to detect specific miRNAs (Liu et al., 2004; Wang et al., 2007). In miRNA microarray, the miRNAs are isolated and labeled with fluorescent dye followed by hybridization with corresponding immobilized microRNA probes on the glass slide (Li and Ruan, 2009). The fluorescence signals emitted from labeled miRNA bound at different spots can be detected.

The use of microarray for clinical diagnostics has been under development for several years. Currently, a variety of microarray systems have been customized for miRNA quantification including GeneChip (Affymetrix), TaqMan ${ }^{\mathrm{TM}}$ Array (Applied Biosystems), miRCURYLNA (Exiqon), and SurePrint (Agilent) (Phua et al., 2014; Wu et al., 2014; Yau et al., 2014). These platforms offer unique advantages in the specific and sensitive detection of miRNA sequences. The probes are designed for specific mature miRNA sequences where the major differences in these platforms include hybridization, washing procedures, and fluorescent dyes. Although miRNA microarray (microchip) is a common method for evaluating known miRNAs, this technology also has some drawbacks. For example, it cannot be utilized for absolute quantification and has a comparative less sensitivity, and is usually considered to have a higher background signal and lower dynamic range than qPCR (Table 2; Reid et al., 2011; Zampetaki and Mayr, 2012). The number of miRNA species that can be detected in a reaction is small and therefore the method of normalization can influence the result (Moldovan et al., 2014).

\section{Digital PCR (dPCR) for Quantifying miRNA in Fecal Samples}

Digital PCR is the latest technology in the PCR arsenal. It is a highly precise approach, and the driving innovation behind it is

TABLE 2 | Advantages and limitations of techniques used to quantify fecal miRNA.

\begin{tabular}{|c|c|c|c|}
\hline Method name & Advantages & Limitations & References \\
\hline qPCR & $\begin{array}{l}\text { - Gold standard for quantification of gene } \\
\text { expression. } \\
\text { - A large dynamic range real-time } \\
\text { monitoring. } \\
\text { - Accurate method for miRNA } \\
\text { quantification. }\end{array}$ & $\begin{array}{l}\text { - Controversy due to different results. } \\
\text { - Genome coverage is very limited. }\end{array}$ & $\begin{array}{l}\text { Heid et al., 1996; Chen et al., 2005; } \\
\text { Schmittgen and Livak, 2008; Balcells } \\
\text { et al., 2011; Yong et al., 2013; Ahmed } \\
\text { et al., } 2017\end{array}$ \\
\hline Microarray & $\begin{array}{l}\text { - Inexpensive, robust, and reliable. } \\
\text { - Ease of use, availability of platforms, } \\
\text { and lower cost relative to other } \\
\text { exploratory methods. }\end{array}$ & $\begin{array}{l}\text { - Lack of rigorous standards for data } \\
\text { collection, analysis, and validation. } \\
\text { - Cannot be utilized for absolute } \\
\text { quantification and have a comparative } \\
\text { less sensitivity. } \\
\text { - Is usually considered to have a higher } \\
\text { background signal and lower dynamic } \\
\text { range than qPCR. }\end{array}$ & $\begin{array}{l}\text { Nakanishi et al., 2001; Conway and } \\
\text { Schoolnik, 2003; Russo et al., 2003; } \\
\text { Jaluria et al., } 2007\end{array}$ \\
\hline Digital PCR & $\begin{array}{l}\text { - Can tolerate PCR inhibitors. } \\
\text { - Time- and reagent-efficient. } \\
\text { - Sensitive and precise absolute } \\
\text { quantification. }\end{array}$ & $\begin{array}{l}\text { - More costly than other detection } \\
\text { methods. }\end{array}$ & $\begin{array}{l}\text { Brunetto et al., 2014; Rački et al., 2014; } \\
\text { Zhao et al., 2015; Stein et al., 2017; } \\
\text { Ahmed et al., 2018a; Quan et al., } 2018\end{array}$ \\
\hline
\end{tabular}


sample partitioning where each partition serves as an individual PCR reaction. Digital PCR can amplify a single molecule a million-fold. In practice, it is well suited to applications requiring accurate quantification, excellent reproducibility, and sensitivity. dPCR can be used as a validated miRNA diagnostic stool test to screen for intestinal-related diseases (Ahmed et al., 2019). This newly introduced approach provides an alternative technique to qPCR for absolute quantification of miRNA. The Quant Studio ${ }^{\text {TM }}$ 3D Digital PCR System and Quant Studio 12K Flex can read the digital chip that contains 20,000 reaction wells in less than $1 \mathrm{~min}$, following thermal cycling. Bio-Rad's droplet PCR is currently commercially available as a third-generation PCR technology. This method, claimed to be of an extraordinary sensitivity, utilizes nanodroplet sample partitioning (Miotto et al., 2014). Droplet dPCR does not require the calibration curves for sample quantification. The digital PCR has the reaction tolerance to PCR inhibitors and is more reproducible than qPCR (Hindson et al., 2013), which is an important advantage on using clinical samples like stool (Sedlak et al., 2014). dPCR assay uses a nanofluidic chip and represents an easy and simple method to run in parallel up to millions of PCR reactions. Ahmed FE et al. reported the analysis of absolute miRNA expression from stool samples by a chip-based dPCR test. The results showed that from a selection of 14 miRNAs, 12 of them showed increased while 2 showed decreased expression (Ahmed et al., 2019). Following the end point PCR, Poisson statistical analysis is applied to determine the absolute quantity of the model containing the numbers of positive and negative observed reactions. The digital PCR approach has several potential benefits over real-time PCR and microarray. This novel method has high sensitivity, precision, and the capability to obtain absolute quantification without external references, making dPCR superior over other methods for many important applications including copy number variation (CNV) and expression analysis.

Samples such as stool that show high inhibition can be assayed using a dPCR, thereby offering a high-throughput and affordable quantitation (Yang et al., 2014). Therefore, dPCR has the potential to have a considerable impact on research, diagnostic, prognostic, and predictive test applications.

\section{CHALLENGES FOR QUANTIFYING MIRNA IN STOOL SAMPLES}

The evaluation of miRNA expression profile in stool samples has applications in diagnosis of several human diseases. However, there are challenges that need to be overcome in order to use miRNAs for this purpose. The following research activities are recommended in order to advance miRNA-guided diagnostics:

\section{REFERENCES}

Absalon, S., Kochanek, D. M., Raghavan, V., and Krichevsky, A. M. (2013). MiR-26b, upregulated in Alzheimer's disease, activates cell cycle entry, tau-phosphorylation, and apoptosis in postmitotic neurons. J. Neurosci. 33, 14645-14659. doi: 10.1523/JNEUROSCI.1327-13. 2013 (i) Designing innovative quantification methods and also improving existing miRNA detection technologies to get better sensitivity and specificity of the test performed.

(ii) Evaluation of cross-platform comparisons of methodologies applied for miRNA detection in stool samples.

(iii) Designing and developing user-friendly online resources to analyze and compare miRNA expression data.

(iv) Conducting a feasibility study for a potential knowledgebased system application of miRNA testing in stool samples for regular use in clinical practice.

\section{CONCLUSION}

Understanding various intestinal diseases requires thorough investigation about the alteration of miRNA functioning and disease progression. An association between alteration of miRNA expression profile and progression of intestinal diseases provides the opportunity to explore new biomarkers in stool samples. So far, biomarkers have been identified in stool for different diseases and new techniques are being developed for high-throughput screening of miRNAs in stool for the diagnosis and prognosis of disease. However, the data on the alteration of miRNA in intestinal diseases and differential profile of miRNA in stool is not complete; more investigation and screening are required for the exploration of new biomarkers.

\section{AUTHOR CONTRIBUTIONS}

HR conceived and designed the study and drafted the manuscript. $\mathrm{HR}, \mathrm{BH}, \mathrm{RH}$, and $\mathrm{MA}$ reviewed the first draft of the manuscript and suggested additional analysis. HR, BH, TS, $\mathrm{ZN}, \mathrm{MK}, \mathrm{MA}$, and $\mathrm{RH}$ revised the final draft manuscript and provided critical comments. All authors read and approved the final version of the manuscript.

\section{ACKNOWLEDGMENTS}

We are grateful to all of the participants for their valuable participation in this study. Current donors include the Government of the People's Republic of Bangladesh; Global Affairs Canada (GAC), Canada; Swedish International Development Cooperation Agency (SIDA); and the Department for International Development (UKAid). 
Ahmed, F. E., Ahmed, N. C., Gouda, M. M., Vos, P. W., and Bonnerup, C. (2018b). RT-qPCR for fecal mature microRNA quantification and validation. Methods Mol. Biol. 1765, 203-215.

Ahmed, F. E., Ahmed, N. C., Vos, P. W., Bonnerup, C., Atkins, J. N., Casey, M., et al. (2013). Diagnostic microRNA markers to screen for sporadic human colon cancer in stool: I. proof of principle. Cancer Genom. Proteom. 10, 93-113.

Ahmed, F. E., Gouda, M. M., Ahmed, N. C., and Hussein, L. (2019). Quantification of micrornas by absolute Dpcr for the diagnostic screening of colon cancer. J. Colon Rect. Cancer 1:10.

Ahmed, F. E., Jeffries, C. D., Vos, P. W., Flake, G., Nuovo, G. J., Sinar, D. R., et al. (2009). Diagnostic microRNA markers for screening sporadic human colon cancer and active ulcerative colitis in stool and tissue. Cancer Genom. Proteom. 6, 281-295.

An, D., Oh, S. F., Olszak, T., Neves, J. F., Avci, F. Y., Erturk-Hasdemir, D., et al. (2014). Sphingolipids from a symbiotic microbe regulate homeostasis of host intestinal natural killer T cells. Cell 156, 123-133. doi: 10.1016/j.cell.2013. 11.042

Balcells, I., Cirera, S., and Busk, P. K. (2011). Specific and sensitive quantitative RTPCR of miRNAs with DNA primers. BMC Biotechnol. 11:70. doi: 10.1186/14726750-11-70

Bastaminejad, S., Taherikalani, M., Ghanbari, R., Akbari, A., and Shabab, N. (2017). Investigation of microRNA-21 expression levels in serum and stool as a potential non-invasive biomarker for diagnosis of colorectal cancer. Iran. Biomed. J. 21:106. doi: 10.18869/acadpub.ibj.21.2.106

Belkaid, Y., and Naik, S. (2013). Compartmentalized and systemic control of tissue immunity by commensals. Nat. Immunol. 14:646. doi: 10.1038/ni.2604

Bi, Y., Liu, G., and Yang, R. (2009). MicroRNAs: novel regulators during the immune response. J. Cell. Physiol. 218, 467-472. doi: 10.1002/jcp.21639

Brunetto, G. S., Massoud, R., Leibovitch, E. C., Caruso, B., Johnson, K., Ohayon, J., et al. (2014). Digital droplet PCR (ddPCR) for the precise quantification of human T-lymphotropic virus 1 proviral loads in peripheral blood and cerebrospinal fluid of HAM/TSP patients and identification of viral mutations. J. Neurovirol. 20, 341-351. doi: 10.1007/s13365-014-0249-3

Buret, A. G., Mitchell, K., Muench, D. G., and Scott, K. G. E. (2002). Giardia lamblia disrupts tight junctional ZO-1 and increases permeability in nontransformed human small intestinal epithelial monolayers: effects of epidermal growth factor. Parasitology 125, 11-19. doi: 10.1017/s0031182002001853

Chen, C., Ridzon, D. A., Broomer, A. J., Zhou, Z., Lee, D. H., Nguyen, J. T., et al. (2005). Real-time quantification of microRNAs by stem-loop RT-PCR. Nucleic Acids Res. 33:e179. doi: 10.1093/nar/gnil78

Cichon, C., Sabharwal, H., Rüter, C., and Schmidt, M. A. (2014). MicroRNAs regulate tight junction proteins and modulate epithelial/endothelial barrier functions. Tissue Barr. 2:e944446. doi: 10.4161/21688362.2014.944446

Conway, T., and Schoolnik, G. K. (2003). Microarray expression profiling: capturing a genome-wide portrait of the transcriptome. Mol. Microbiol. 47, 879-889. doi: 10.1046/j.1365-2958.2003.03338.x

De Magistris, L., Secondulfo, M., Sapone, A., Carratú, R., Iafusco, D., Prisco, F., et al. (2003). Infection with Giardia and intestinal permeability in humans. Gastroenterology 125, 277-279. doi: 10.1016/s0016-5085(03)00822-9

Fukui, H. (2016). Increased intestinal permeability and decreased barrier function: does it really influence the risk of inflammation? Inflamm. Intest. Dis. 1, 135-145. doi: 10.1159/000447252

Groschwitz, K. R., and Hogan, S. P. (2009). Intestinal barrier function: molecular regulation and disease pathogenesis. J. Allergy Clin. Immunol. 124, 3-20. doi: 10.1016/j.jaci.2009.05.038

Haines, R. J., Beard, R. S. Jr., Eitner, R. A., Chen, L., and Wu, M. H. (2016). TNF $\alpha /$ IFN $\gamma$ mediated intestinal epithelial barrier dysfunction is attenuated by microRNA-93 downregulation of PTK6 in mouse colonic epithelial cells. PLoS One 11:154351. doi: 10.1371/journal.pone.0154351

Hammond, S. M., Bernstein, E., Beach, D., and Hannon, G. J. (2000). An RNAdirected nuclease mediates post-transcriptional gene silencing in Drosophila cells. Nature 404, 293-296. doi: 10.1038/35005107

Heid, C. A., Stevens, J., Livak, K. J., and Williams, P. M. (1996). Real time quantitative PCR. Genome Res. 6, 986-994. doi: 10.1101/gr.6.10.986

Hibner, G., Kimsa-Furdzik, M., and Francuz, T. (2018). Relevance of microRNAs as potential diagnostic and prognostic markers in colorectal cancer. Intern. J. Mol. Sci. 19:2944. doi: 10.3390/ijms19102944
Hindson, C. M., Chevillet, J. R., Briggs, H. A., Gallichotte, E. N., Ruf, I. K., Hindson, B. J., et al. (2013). Absolute quantification by droplet digital PCR versus analog real-time PCR. Nat. Methods 10:1003. doi: 10.1038/nmeth.2633

Ho, B. C., Yang, P. C., and Yu, S. L. (2016). MicroRNA and pathogenesis of enterovirus infection. Viruses 8:v8010011. doi: 10.3390/v8010011

Hossain, M. I., Haque, R., Mondal, D., Mahfuz, M., Ahmed, A. S., Islam, M. M., et al. (2016). Undernutrition, vitamin A and iron deficiency are associated with impaired intestinal mucosal permeability in young Bangladeshi children assessed by lactulose/mannitol test. PLoS One 11:e0164447. doi: 10.1371/ journal.pone.0164447

Iannone, A., Losurdo, G., Pricci, M., Girardi, B., Massaro, A., Principi, M., et al. (2016). Stool investigations for colorectal cancer screening: from occult blood test to DNA analysis. J. Gastrointest. Cancer 47, 143-151. doi: 10.1007/s12029016-9810-z

Iborra, M., Bernuzzi, F., Correale, C., Vetrano, S., Fiorino, G., Beltrán, B., et al. (2013). Identification of serum and tissue micro-RNA expression profiles in different stages of inflammatory bowel disease. Clin. Exper. Immunol. 173, 250-258. doi: 10.1111/cei.12104

Ivey, K. N., and Srivastava, D. (2015). microRNAs as developmental regulators. Cold Spring Harb. Perspect. Biol. 7:a008144. doi: 10.1101/cshperspect.a008144

Jaluria, P., Konstantopoulos, K., Betenbaugh, M., and Shiloach, J. (2007). A perspective on microarrays: current applications, pitfalls, and potential uses. Microb. Cell Fact. 6:4. doi: 10.1186/1475-2859-6-4

Kato, J., Hiraoka, S., Nakarai, A., Takashima, S., Inokuchi, T., and Ichinose, M. (2016). Fecal immunochemical test as a biomarker for inflammatory bowel diseases: can it rival fecal calprotectin? Intest. Res. 14:5. doi: 10.5217/ir.2016. 14.1 .5

Koga, Y., Yasunaga, M., Moriya, Y., Akasu, T., Fujita, S., Yamamoto, S., et al. (2011). Exosome can prevent RNase from degrading microRNA in feces. J. Gastrointest. Oncol. 2:215.

Li, W., and Ruan, K. (2009). MicroRNA detection by microarray. Analyt. Bioanalyt. Chem. 394, 1117-1124. doi: 10.1007/s00216-008-2570-2

Li, X., Zhang, Y., Zhang, Y., Ding, J., Wu, K., and Fan, D. (2010). Survival prediction of gastric cancer by a seven-microRNA signature. Gut 59, 579-585. doi: 10.1136/gut.2008.175497

Lin, S., and Gregory, R. I. (2015). MicroRNA biogenesis pathways in cancer. Nat. Rev. Cancer 15:321. doi: 10.1038/nrc3932

Link, A., Balaguer, F., Shen, Y., Nagasaka, T., Lozano, J. J., Boland, C. R., et al. (2010). Fecal MicroRNAs as novel biomarkers for colon cancer screening. Cancer Epidemiol. Prevent. Biomark. 19, 1766-1774. doi: 10.1158/1055-9965. EPI-10-0027

Link, A., Becker, V., Goel, A., Wex, T., and Malfertheiner, P. (2012). Feasibility of fecal microRNAs as novel biomarkers for pancreatic cancer. PLoS One 7:e42933. doi: 10.1371/journal.pone.0042933

Liu, C. G., Calin, G. A., Meloon, B., Gamliel, N., Sevignani, C., Ferracin, M., et al. (2004). An oligonucleotide microchip for genome-wide microRNA profiling in human and mouse tissues. Proc. Natl. Acad. Sci. U.S.A. 101, 9740-9744. doi: 10.1073/pnas.0403293101

Liu, S., da Cunha, A. P., Rezende, R. M., Cialic, R., Wei, Z., Bry, L., et al. (2016). The host shapes the gut microbiota via fecal microRNA. Cell Host Microb. 19, 32-43. doi: 10.1016/j.chom.2015.12.005

Maudet, C., Mano, M., and Eulalio, A. (2014). MicroRNAs in the interaction between host and bacterial pathogens. FEBS Lett. 588, 4140-4147. doi: 10.1016/ j.febslet.2014.08.002

McManus, D. D., and Ambros, V. (2011). Circulating MicroRNAs in cardiovascular disease. Circulation 124, 1908-1910. doi: 10.1161/ CIRCULATIONAHA.111.062117

Miotto, E., Saccenti, E., Lupini, L., Callegari, E., Negrini, M., and Ferracin, M. (2014). Quantification of circulating miRNAs by droplet digital PCR: comparison of EvaGreen-and TaqMan-based chemistries. Cancer Epidemiol. Biomark. Prev. 23, 2638-2642. doi: 10.1158/1055-9965

Moldovan, L., Batte, K. E., Trgovcich, J., Wisler, J., Marsh, C. B., and Piper, M. (2014). Methodological challenges in utilizing mi RNA s as circulating biomarkers. J. Cell. Mol. Med. 18, 371-390. doi: 10.1111/jcmm.12236

Moloney, G. M., Viola, M. F., Hoban, A. E., Dinan, T. G., and Cryan, J. F. (2018). Faecal microRNAs: indicators of imbalance at the host-microbe interface? Benef. Microb. 9, 175-183. doi: 10.3920/BM2017.0013 
Mondal, D., Minak, J., Alam, M., Liu, Y., Dai, J., Korpe, P., et al. (2012). Contribution of enteric infection, altered intestinal barrier function, and maternal malnutrition to infant malnutrition in Bangladesh. Clin. Infect. Dis. 54, 185-192. doi: 10.1093/cid/cir807

Montecalvo, A., Larregina, A. T., Shufesky, W. J., Stolz, D. B., Sullivan, M. L., Karlsson, J. M., et al. (2012). Mechanism of transfer of functional microRNAs between mouse dendritic cells via exosomes. Blood 119, 756-766. doi: 10.1182/ blood-2011-02-338004

Nakanishi, T., Oka, T., and Akagi, T. (2001). Recent advances in DNA microarrays. Acta Med. Okayama 55, 319-328. doi: 10.18926/AMO/32002

O’Brien, J., Hayder, H., Zayed, Y., and Peng, C. (2018). Overview of microRNA biogenesis, mechanisms of actions, and circulation. Front. Endocrinol. 9:402. doi: 10.3389/fendo.2018.00402

Owczarzy, R., You, Y., Groth, C. L., and Tataurov, A. V. (2011). Stability and mismatch discrimination of locked nucleic acid-DNA duplexes. Biochemistry 50, 9352-9367. doi: 10.1021/bi200904e

Paula, V. S. D., Villar, L. M., and Gaspar, A. M. C. (2003). Comparison of four extraction methods to detect hepatitis A virus RNA in serum and stool samples. Braz. J. Infect. Dis. 7, 135-141. doi: 10.1590/s1413-86702003000200007

Petri, W. A. Jr., Naylor, C., and Haque, R. (2014). Environmental enteropathy and malnutrition: do we know enough to intervene? BMC Med. 12:187. doi: 10.1186/s12916-014-0187-1

Phua, L. C., Chue, X. P., Koh, P. K., Cheah, P. Y., Chan, E. C. Y., and Ho, H. K. (2014). Global fecal microRNA profiling in the identification of biomarkers for colorectal cancer screening among Asians. Oncol. Rep. 32, 97-104. doi: 10.3892/or.2014.3193

Quan, P.-L., Sauzade, M., and Brouzes, E. (2018). dPCR: a technology review. Sensors 18:1271. doi: 10.3390/s18041271

Rački, N., Dreo, T., Gutierrez-Aguirre, I., Blejec, A., and Ravnikar, M. (2014), Reverse transcriptase droplet digital PCR shows high resilience to PCR inhibitors from plant, soil and water samples. Plant Methods 10:42. doi: 10.1186/ s13007-014-0042-6

Reid, G., Kirschner, M. B., and van Zandwijk, N. (2011). Circulating microRNAs: association with disease and potential use as biomarkers. Crit. Rev. Oncol. 80, 193-208. doi: 10.1016/j.critrevonc.2010.11.004

Ren, A., Dong, Y., Tsoi, H., and Yu, J. (2015). Detection of miRNA as noninvasive biomarkers of colorectal cancer. Intern. J. Mol. Sci. 16, 2810-2823. doi: $10.3390 /$ ijms 16022810

Ro, S., Park, C., Jin, J., Sanders, K. M., and Yan, W. (2006). A PCR-based method for detection and quantification of small RNAs. Biochem. Biophys. Res. Commun. 351, 756-763. doi: 10.1016/j.bbrc.2006.10.105

Russo, G., Zegar, C., and Giordano, A. (2003). Advantages and limitations of microarray technology in human cancer. Oncogene 22:6497. doi: 10.1038/sj.onc. 1206865

Schmittgen, T. D., and Livak, K. J. (2008). Analyzing real-time PCR data by the comparative C T method. Nat. Protoc. 3:1101. doi: 10.1038/nprot.2008.73

Schönauen, K., Le, N., von Arnim, U., Schulz, C., Malfertheiner, P., and Link, A. (2018). Circulating and Fecal microRNAs as Biomarkers for Inflammatory Bowel Diseases. Inflamm. Bowel Dis. 24, 1547-1557. doi: 10.1093/ibd/izy046

Sedlak, R. H., Kuypers, J., and Jerome, K. R. (2014). A multiplexed droplet digital PCR assay performs better than qPCR on inhibition prone samples. Diagn. Microbiol. Infect. Dis. 80, 285-286. doi: 10.1016/j.diagmicrobio.2014.09.004

Sheedy, F., and O'neill, L. (2008). Adding fuel to fire: microRNAs as a new class of mediators of inflammation. Anna. Rheum. Dis. 67(Suppl. 3), iii50-iii55. doi: $10.1136 /$ ard.2008.100289

Shi, R., and Chiang, V. L. (2005). Facile means for quantifying microRNA expression by real-time PCR. Biotechniques 39, 519-525. doi: 10.2144/ 000112010

Shulman, R. J., Eakin, M. N., Czyzewski, D. I., Jarrett, M., and Ou, C.-N. (2008). Increased gastrointestinal permeability and gut inflammation in children with functional abdominal pain and irritable bowel syndrome. J. Pediatr. 153, 646650. doi: 10.1016/j.jpeds.2008.04.062

Simadibrata, M. (2010). The role of fecal occult blood test in screening of colorectal cancer and inflammatory bowel disease. Ind. J. Gastroenterol. Hepatol. Digest. Endosc. 11, 35-39. doi: 10.24871/111201035-39

Skalsky, R. L., and Cullen, B. R. (2010). Viruses, microRNAs, and host interactions. Annu. Rev. Microbiol. 64, 123-141. doi: 10.1146/annurev.micro.112408.13 4243
Spiceland, C. M., and Lodhia, N. (2018). Endoscopy in inflammatory bowel disease: role in diagnosis, management, and treatment. World J. Gastroenterol. 24:4014. doi: 10.3748/wjg.v24.i35.4014

Stein, E. V., Duewer, D. L., Farkas, N., Romsos, E. L., Wang, L., and Cole, K. D. (2017). Steps to achieve quantitative measurements of microRNA using two step droplet digital PCR. PLoS One 12:e0188085. doi: 10.1371/journal.pone. 0188085

Tarallo, S., Pardini, B., Mancuso, G., Rosa, F., Di Gaetano, C., Rosina, F., et al. (2014). MicroRNA expression in relation to different dietary habits: a comparison in stool and plasma samples. Mutagenesis 29, 385-391. doi: 10. 1093/mutage/geu028

Thomson, J. M., Parker, J. S., and Hammond, S. M. (2007). Microarray analysis of miRNA gene expression. Methods Enzymol. 427, 107-122. doi: 10.1016/S00766879(07)27006-5

Turchinovich, A., and Cho, W. (2014). The origin, function and diagnostic potential of extracellular microRNA in human body fluids. Front. Genet. 5:30. doi: 10.3389/fgene.2014.00030

Valencia-Sanchez, M. A., Liu, J., Hannon, G. J., and Parker, R. (2006). Control of translation and mRNA degradation by miRNAs and siRNAs. Genes Dev. 20, 515-524. doi: 10.1101/gad.1399806

Verdier, J., Breunig, I. R., Ohse, M. C., Roubrocks, S., Kleinfeld, S., Roy, S., et al. (2019). Faecal micro-RNAs in inflammatory bowel diseases. J. Crohn Colitis 14, 110-117. doi: 10.1093/ecco-jcc/jjz120

Viennois, E., Chassaing, B., Tahsin, A., Pujada, A., Wang, L., Gewirtz, A. T., et al. (2019). Host-derived fecal microRNAs can indicate gut microbiota healthiness and ability to induce inflammation. Theranostics 9:4542. doi: 10.7150/thno. 35282

Wahlgren, J., Karlson, T. D. L., Brisslert, M., Vaziri Sani, F., Telemo, E., Sunnerhagen, P., et al. (2012). Plasma exosomes can deliver exogenous short interfering RNA to monocytes and lymphocytes. Nucleic Acids Res. 40:e130. doi: $10.1093 / \mathrm{nar} / \mathrm{gks} 463$

Wan, J., Xia, L., Xu, W., and Lu, N. (2016). Expression and Function of miR155 in diseases of the gastrointestinal tract. Intern. J. Mol. Sci. 17:709. doi: 10.3390/ijms 17050709

Wang, H., Ach, R. A., and Curry, B. (2007). Direct and sensitive miRNA profiling from low-input total RNA. RNA 13, 151-159. doi: 10.1261/rna.234507

Weber, J. A., Baxter, D. H., Zhang, S., Huang, D. Y., Huang, K. H., Lee, M. J., et al. (2010). The microRNA spectrum in 12 body fluids. Clin. Chem. 56, 1733-1741. doi: 10.1373/clinchem.2010.147405

Wohnhaas, C. T., Schmid, R., Rolser, M., Kaaru, E., Langgartner, D., Rieber, K., et al. (2020). Fecal MicroRNAs show promise as noninvasive Crohn's disease biomarkers. Crohn's Colitis 360:otaa003. doi: 10.1093/crocol/otaa003

Wu, C. W., Ng, S. C., Dong, Y., Tian, L., Ng, S. S. M., Leung, W. W., et al. (2014). Identification of microRNA-135b in stool as a potential noninvasive biomarker for colorectal cancer and adenoma. Clin. Cancer Res. 20, 2994-3002. doi: 10.1158/1078-0432.CCR-13-1750

Wu, C. W., Ng, S. S., Dong, Y. J., Ng, S. C., Leung, W. W., Lee, C. W., et al. (2012). Detection of miR-92a and miR-21 in stool samples as potential screening biomarkers for colorectal cancer and polyps. Gut 61, 739-745. doi: 10.1136/gut. 2011.239236

Wu, L., Fan, J., and Belasco, J. G. (2006). MicroRNAs direct rapid deadenylation of mRNA. Proc. Natl. Acad. Sci. U.S.A. 103, 4034-4039. doi: 10.1073/pnas. 0510928103

Yang, R., Paparini, A., Monis, P., and Ryan, U. (2014). Comparison of nextgeneration droplet digital PCR (ddPCR) with quantitative PCR (qPCR) for enumeration of Cryptosporidium oocysts in faecal samples. Intern. J. Parasitol. 44, 1105-1113. doi: 10.1016/j.ijpara.2014.08.004

Yang, Y., Ma, Y., Shi, C., Chen, H., Zhang, H., Chen, N., et al. (2013). Overexpression of miR-21 in patients with ulcerative colitis impairs intestinal epithelial barrier function through targeting the Rho GTPase RhoB. Biochem. Biophys. Res. Commun. 434, 746-752. doi: 10.1016/j.bbrc.2013.03.122

Yau, T., Wu, C., Dong, Y., Tang, C., Ng, S., Chan, F., et al. (2014). microRNA221 and microRNA-18a identification in stool as potential biomarkers for the non-invasive diagnosis of colorectal carcinoma. Br. J. Cancer 111:1765. doi: $10.1038 /$ bjc. 2014.484

Ye, D., Guo, S., Al-Sadi, R., and Ma, T. Y. (2011). MicroRNA regulation of intestinal epithelial tight junction permeability. Gastroenterology 141, 1323-1333. doi: 10.1053/j.gastro.2011.07.005 
Yong, F. L., Law, C. W., and Wang, C. W. (2013). Potentiality of a triple microRNA classifier: miR-193a-3p, miR-23a and miR-338-5p for early detection of colorectal cancer. BMC Cancer 13:280. doi: 10.1186/1471-240713-280

Yu, L. C.-H. (2018). Microbiota dysbiosis and barrier dysfunction in inflammatory bowel disease and colorectal cancers: exploring a common ground hypothesis. J. Biomed. Sci. 25, 1-14. doi: 10.1186/s12929-018-0483-8

Zampetaki, A., and Mayr, M. (2012). Analytical challenges and technical limitations in assessing circulating miRNAs. Thromb. Haemost. 108, 592-598. doi: 10.1160/ TH12-02-0097

Zhang, B., Tian, Y., Jiang, P., Jiang, Y., Li, C., Liu, T., et al. (2017). MicroRNA-122a regulates zonulin by targeting EGFR in intestinal epithelial dysfunction. Cell. Physiol. Biochem. 42, 848-858. doi: 10.1159/000478629

Zhang, J.-X., Song, W., Chen, Z.-H., Wei, J.-H., Liao, Y.-J., Lei, J., et al. (2013). Prognostic and predictive value of a microRNA signature in stage II colon cancer: a microRNA expression analysis. Lancet Oncol. 14, 1295-1306. doi: 10.1016/S1470-2045(13)70491-1

Zhang, L., Shen, J., Cheng, J., and Fan, X. (2015). MicroRNA-21 regulates intestinal epithelial tight junction permeability. Cell Biochem. Funct. 33, 235-240. doi: $10.1002 / \mathrm{cbf} .3109$

Zhao, S., Lin, H., Chen, S., Yang, M., Yan, Q., Wen, C., et al. (2015). Sensitive detection of Porcine circovirus-2 by droplet digital polymerase chain reaction. J. Vet. Diagn. Invest. 27, 784-788. doi: 10.1177/1040638715608358
Zheng, Y., Cai, X., and Bradley, J. E. (2013). microRNAs in parasites and parasite infection. RNA Biol. 10, 371-379. doi: 10.4161/rna.23716

Zhou, Y., Wu, J., Geng, P., Kui, X., Xie, Y., Zhang, L., et al. (2016). MicroRNA profile analysis of host cells before and after wild human rotavirus infection. J. Med. Virol. 88, 1497-1510. doi: 10.1002/jmv.24500

Zhu, Y., Xu, A., Li, J., Fu, J., Wang, G., Yang, Y., et al. (2016). Fecal miR-29a and miR-224 as the noninvasive biomarkers for colorectal cancer. Cancer Biomark. 16, 259-264. doi: 10.3233/CBM- 150563

Disclaimer: The authors alone are responsible for the views expressed in this manuscript.

Conflict of Interest: The authors declare that the research was conducted in the absence of any commercial or financial relationships that could be construed as a potential conflict of interest.

Copyright (C) 2020 Rashid, Hossain, Siddiqua, Kabir, Noor, Ahmed and Haque. This is an open-access article distributed under the terms of the Creative Commons Attribution License (CC BY). The use, distribution or reproduction in other forums is permitted, provided the original author(s) and the copyright owner(s) are credited and that the original publication in this journal is cited, in accordance with accepted academic practice. No use, distribution or reproduction is permitted which does not comply with these terms. 